\title{
Quantitative Electron-excited X-ray Microanalysis with Low Energy L-Peaks
}

\author{
Dale Newbury and Nicholas Ritchie
}

National Institute of Standards and Technology, Gaithersburg, Maryland, United States

Quantitative electron-excited X-ray microanalysis following the standards-based intensity-ratio ("kratio") method with matrix corrections, as originated by Castaing, is capable of achieving high accuracy results [1,2]. When tested against known homogeneous materials, $95 \%$ or more of analyses of major (mass concentration $\mathrm{C}>0.1)$ and minor $(0.01 \leq \mathrm{C} \leq 0.1)$ elemental constituents fall within a relative deviation from expected value of $\pm 5 \%(\mathrm{RDEV}=\{[$ measured value - reference value $] /$ reference value ${ }^{*} 100 \%$ ) [3]. Achieving this accuracy requires only a simple standards suite that consists of pure elements, and for those elements that are reactive, e.g., Ca, gaseous, e.g., F, or degrade under electron bombardment, e.g., S, a stoichiometric compound can be utilized, e.g., $\mathrm{CaF}_{2}, \mathrm{FeS}_{2}$, etc. Because each constituent is measured against its own standard, the raw analytical total, which is the sum of all constituents including any such as $\mathrm{O}$ calculated by the method of assumed stoichiometry, provides a useful internal quality measure. The analytical total typically falls in the range 0.98 to 1.02 mass fraction. Excursions outside this range may indicate a deviation in measurement conditions, the presence of a surface layer due to oxidation or contamination on the sample and/or standard, or for totals below unity, the additional possibility of an unmeasured constituent [4]. Thus, the report by Llovet et al. [5] of an unexpected and sharp departure of the analytical total from this range when analyzing a series of Ni-Si intermetallic compounds with the $\mathrm{Ni} \mathrm{L}_{3}-\mathrm{M}_{4,5}$ peak at $0.851 \mathrm{keV}$, as measured with wavelength dispersive spectrometry (WDS) against pure element standards, reveals a remarkable breakdown of standards-based analysis. This presentation examines the analysis of several materials representing a range of low energy L-family peaks from $\mathrm{Fe}\left(\mathrm{L}_{3}-\mathrm{M}_{4,5}, 0.704 \mathrm{keV}\right)$ to $\mathrm{Se}\left(\mathrm{L}_{3}-\mathrm{M}_{4,5}, 1.379 \mathrm{keV}\right)$ as measured with energy dispersive spectrometry (EDS) and quantified with NIST DTSA-II [6].

Table 1 presents EDS results for NiSi and NiSi2, analyzed with pure Ni and $\mathrm{Si}$ as the peak fitting references and standards. Using the Ni L-family, extreme deviations from a unity analytical total are observed, with the deviation increasing as the beam energy (and overvoltage) increases. (Note that analyzing these same spectra with the Ni K-family resulted in analytical totals near unity and small RDEV values.) The analytical totals are so extreme that only by calculating normalized mass concentrations can the concentrations be sensibly compared for measurements at different beam energies. Even after normalization, the RDEVs of the normalized mass concentrations for Ni show such large deviations from the ideal composition as to greatly diminish the utility of the analytical results for practical applications. Similar behavior is found in Table 1 for analysis of alloys and stoichiometric compounds using the low energy L-family peaks for $\mathrm{Fe}, \mathrm{Co}$, and Ge when a pure element serves as the fitting reference and standard. However, as shown in Table 2, when the L-shell element of interest is analyzed with that element in a stoichiometric compound or a multi-element glass serving as the peak fitting reference and standard, the analytical totals are generally brought back into an acceptable range near unity and the RDEV values generally fall within $\pm 5 \%$, with a few exceptions. Note the magnitude of this effect: for example, for $\mathrm{NiSi}$ at $10 \mathrm{keV}$ (overvoltage $\mathrm{UNiL}=11.7$ ) the analytical total for L-family analysis with pure $\mathrm{Ni}$ is 1.607 with an RDEV of $11 \%$ for Ni while with $\mathrm{Al}_{3} \mathrm{Ni}$ the total is 1.015 with an RDEV of $0.9 \%$. For the systems examined in this study, the use of compound standards provides a huge improvement in the analytical total and the RDEV for analysis with the low energy L-family X-rays. The origin of the obvious 
disconnection between the use of pure element standards and compound standards is the subject of continuing research.

Table 1 Analysis of various materials using the L-family and pure elements as peak fitting references and standards

\begin{tabular}{|c|c|c|c|c|c|c|c|}
\hline $\begin{array}{l}\text { Analyzed } \\
\text { material }\end{array}$ & \begin{tabular}{||l} 
Peak \\
Fitting \\
Reference
\end{tabular} & Standard & L-3 energy & \begin{tabular}{|l} 
Beam \\
energy \\
$(\mathrm{keV})$
\end{tabular} & $\mid \begin{array}{l}\text { L- } \\
\text { overvoltage }\end{array}$ & $\begin{array}{l}\text { Analytical } \\
\text { total }\end{array}$ & $\left(\begin{array}{l}\text { RDEV } \\
(\text { norm } \\
\text { mass conc) } \\
\text { L }\end{array}\right.$ \\
\hline $\mathrm{NiSi}$ & Ni & Ni & 0.853 & || 15 & $\mid 17.6$ & 2.229 & $34 \%$ \\
\hline $\mathrm{NiSi}$ & $\mathrm{Ni}$ & Ni & 0.853 & $\mid 10$ & $\mid 11.7$ & $\mid$\begin{tabular}{||l}
$\mid 1.607$ \\
|
\end{tabular} & $\mid 11 \%$ \\
\hline $\mathrm{NiSi}$ & Ni & Ni & 0.853 & 5 & $\mid 5.9$ & $\mid 1.186$ & $6.7 \%$ \\
\hline $\mathrm{NiSi}_{2}$ & Ni & Ni & 0.853 & $\mid 15$ & $\mid 17.6$ & $\mid 3.327$ & $\mid 31 \%$ \\
\hline $\mathrm{NiSi}_{2}$ & Ni & Ni & 0.853 & 10 & $\mid 11.7$ & ||1.687 & $25 \%$ \\
\hline $\mathrm{NiSi}_{2}$ & $\mathrm{Ni}$ & Ni & 0.853 & $\mid 5$ & $\mid 5.9$ & $\mid 1.169$ & $16 \%$ \\
\hline & & & & & & & \\
\hline
\end{tabular}




\begin{tabular}{|c|c|c|c|c|c|c|c|}
\hline $\mathrm{FeAl}_{3}$ & $\mathrm{Fe}$ & $\mid \mathrm{Fe}$ & 0.708 & 20 & 28.2 & 1.294 & $4.7 \%$ \\
\hline $\mathrm{FeAl}_{3}$ & $\mathrm{Fe}$ & $\mid \mathrm{Fe}$ & 0.708 & 15 & 21.2 & 1.198 & $6.6 \%$ \\
\hline $\mathrm{FeAl}_{3}$ & $\mathrm{Fe}$ & $\mid \mathrm{Fe}$ & 0.708 & 10 & $\mid 14.1$ & 1.128 & $8.5 \%$ \\
\hline Co-Ta alloy & $\mathrm{Co}$ & |Co & $\mid 0.779$ & 15 & $\mid 19.3$ & 1.555 & $8.8 \%$ \\
\hline Co-Ta alloy & Co & ||Co & 0.779 & 10 & $\mid 12.8$ & 1.406 & $9.0 \%$ \\
\hline Co-Ta alloy & $\mathrm{Co}$ & |Co & 0.779 & 5 & 6.4 & 1.207 & $5.8 \%$ \\
\hline GeTe & $\mathrm{Ge}$ & Ge & $\mid 1.217$ & 20 & $\mid 16.4$ & 0.8373 & $-30 \%$ \\
\hline GeTe & $\mathrm{Ge}$ & Ge & $\mid 1.217$ & 15 & $\mid 12.3$ & 0.9073 & $-19 \%$ \\
\hline GeTe & $\mathrm{Ge}$ & Ge & || 1.217 & 10 & | 8.2 & 0.9595 & $\mid-10 \%$ \\
\hline
\end{tabular}


Table 2 Analysis of various materials using the L-family and mixtures as peak fitting references and standards

\begin{tabular}{|c|c|c|c|c|c|c|c|}
\hline $\begin{array}{l}\text { Analyzed } \\
\text { material }\end{array}$ & \begin{tabular}{|l} 
Peak \\
Fitting \\
Reference
\end{tabular} & Standard & L-3 energy & $\begin{array}{l}\text { Beam } \\
\text { energy } \\
(\mathrm{keV})\end{array}$ & $\mid \begin{array}{l}\text { L- } \\
\text { overvoltage }\end{array}$ & $\begin{array}{l}\text { Analytical } \\
\text { total }\end{array}$ & $\mid \begin{array}{l}\text { RDEV } \\
\text { (norm } \\
\text { mass conc) } \\
\text { L }\end{array}$ \\
\hline $\mathrm{NiSi}$ & $\mathrm{Al}_{3} \mathrm{Ni}$ & $\mathrm{Al}_{3} \mathrm{Ni}$ & 0.853 & $\mid 15$ & $\mid 17.6$ & 1.087 & $\mid 1.2 \%$ \\
\hline $\mathrm{NiSi}$ & $\mathrm{Al}_{3} \mathrm{Ni}$ & $\mathrm{Al}_{3} \mathrm{Ni}$ & 0.853 & $\mid 10$ & || 11.7 & 1.015 & $0.9 \%$ \\
\hline $\mathrm{NiSi}$ & $\mathrm{Al}_{3} \mathrm{Ni}$ & $\mathrm{Al}_{3} \mathrm{Ni}$ & 0.853 & $\mid 5$ & $\mid 5.9$ & 1.014 & $0.32 \%$ \\
\hline $\mathrm{NiSi}_{2}$ & $\mathrm{Al}_{3} \mathrm{Ni}$ & $\mathrm{Al}_{3} \mathrm{Ni}$ & 0.853 & 15 & $\mid 17.6$ & 1.097 & | $9.9 \%$ \\
\hline $\mathrm{NiSi} 2$ & $\mathrm{Al}_{3} \mathrm{Ni}$ & $\mathrm{Al}_{3} \mathrm{Ni}$ & 0.853 & $\mid 10$ & || 11.7 & 1.040 & $7.3 \%$ \\
\hline $\mathrm{NiSi} 2$ & $\mathrm{Al}_{3} \mathrm{Ni}$ & $\mathrm{Al}_{3} \mathrm{Ni}$ & 0.853 & |5 & $\mid 5.9$ & 1.018 & $5.6 \%$ \\
\hline & & & 0.708 & $\mid 20$ & 28.2 & 1.043 & $\mid-1.9 \%$ \\
\hline
\end{tabular}




\begin{tabular}{|c|c|c|c|c|c|c|c|}
\hline $\mathrm{FeAl}_{3}$ & $\mathrm{FeS}_{2}$ & $\mathrm{FeS}_{2}$ & & & & & \\
\hline $\mathrm{FeAl}_{3}$ & $\mathrm{FeS}_{2}$ & $\mathrm{FeS}_{2}$ & 0.708 & $\mid 15$ & 21.2 & 1.011 & $\mid-2.4 \%$ \\
\hline $\mathrm{FeAl}_{3}$ & $\mathrm{FeS}_{2}$ & $\mathrm{FeS}_{2}$ & 0.708 & $\mid 10$ & 14.1 & 0.9874 & $\mid-3.4 \%$ \\
\hline Co-Ta alloy & Co-W alloy & Co-W alloy & 0.779 & $\mid 15$ & $\mid 19.3$ & 1.016 & $-1.6 \%$ \\
\hline Co-Ta alloy & Co-W alloy & Co-W alloy & 0.779 & $\mid 10$ & $\mid 12.8$ & 1.009 & $0.22 \%$ \\
\hline Co-Ta alloy & Co-W alloy & Co-W alloy & 0.779 & $\mid 5$ & 6.4 & 1.034 & $\mid-3.0 \%$ \\
\hline GeTe & $\mathrm{Ge}$ & SRM1872 & $\mid 1.217$ & $\mid 20$ & $\mid 16.4$ & 1.011 & $\mid-3.1 \%$ \\
\hline GeTe & $\mathrm{Ge}$ & SRM1872 & $\mid 1.217$ & $\mid 15$ & $\mid 12.3$ & 1.028 & $\mid-0.09 \%$ \\
\hline GeTe & $\mathrm{Ge}$ & SRM1872 & || 1.217 & $\mid 10$ & 8.2 & 1.015 & $-1.7 \%$ \\
\hline
\end{tabular}




\section{References}

1. Castaing, R., Ph. D. Thesis, "Application of electron probes to local chemical and crystallographic analysis," University of Paris (1951).

2. Goldstein, J., Newbury, D., Michael, J., Ritchie, N., Scott, J., and Joy, D., Scanning Electron Microscopy and X-ray Microanalysis, $4^{\text {th }}$ ed. (Springer, New York, 2018).

3. Newbury, D. and Ritchie, N., Micros. Microanal., 25 (2019) 1075-1105.

4. Newbury, D. and Ritchie, N., Micros. Microanal. (Suppl 2) 25 (2019) 446-447.

5. Llovet, X., Pinard, P., Heikinheimo, E., Louhenkilpi, S., and Richter, S., Micros. Microanal., 22 (2016) 1233-1243.

6. Ritchie, N. (2018). NIST DTSA-II software, including tutorials. Available for free at: http://www.cstl.nist.gov/div837/837.02/epq/dtsa2/index.html (retrieved December 19, 2019). 